\title{
FutureJournal
}

\section{Radical Innovation, Paradigm Shift and Incumbent's Dilemma The Case of the Auto Industry}

\author{
Eden Yin \\ Judge Business School, University of Cambridge, Cambridge, UK \\ e.yin@jbs.cam.ac.uk \\ Shaz Ansari \\ Judge Business School, University of Cambridge, Cambridge, UK \\ s.ansari@jbs.cam.ac.uk \\ Naseem Akhtar \\ Jaguar Land Rover Limited, Coventry, UK \\ naseem@iname.com
}

\section{Introduction}

Radical innovations often upend incumbents firms and can even render them obsolete (Ansari \& Krop, 2012; Benner, 2010). Incumbents often have great difficulties in addressing the challenge posed by radical innovations due to inertia (Ghemawat, 1991), tendencies to exploit existing competences (Levinthal \& March, 1993; O'Reilly \& Tushman, 2008), organizational rigidity (Beonard-Barton, 1992), complacency and internal culture (Tellis, 2006), inadequacies in the incentive system and resource allocation process (Christensen, 1997), and gaps in organizational capabilities required for embracing the innovation (Henderson, 2006; Tushman \& Anderson, 1986). However, a growing number of industries confront the threat of radical innovations, responding to this them has become a strategic priority for many incumbent firms.

Research shows that incumbents can survive or even prosper in the face of radical innovations by forging effective partnerships with challenger firms (Ansari \& Krop, 2012), establishing a separate entity to fend off the threat (Christensen, 1997; Christensen, Raynor \& McDonald, 2015), better evaluation and investment approaches (Hill \& Rothaermel, 2003), appropriate configuration of organizational form and structure (Ansari \& Krop, 2012), coupling basic and applied research functions (Hill \& Rothaermel, 2003), possessing downstream complementary assets critical for commercializing the new technology (Ansari \& Krop, 2012; Hill \& Rothaermel, 2003), and a high willingness to cannibalize their core business (Chandy and Tellis, 1998). 


\section{FutureJournal}

Profuturo: Future Studies Program

Incumbents can also thrive or overcome the so-called incumbent's curse by pioneering radical innovations by themselves - self disruption (Chandy and Tellis, 2000).

Extant studies on radical innovations focus primarily on a single product (e.g., Chandy and Tellis, 1998, 2000), technological or business model innovation (Ansari \& Krop, 2012; Christensen, 1997; Hill \& Rothaermel, 2003). These innovations may have the potential to shrink the incumbents' marketspace, e.g., Gemesis' synthetic diamonds challenging the natural diamonds (McAdams and Reavis, 2008), EasyJet challenging mainstream airlines such as BA, Netflix challenging the traditional movie rental business like Blockbusters (Leonhartdt, 2006), or displace the incumbent market leader, e.g., IBM PC and its clones destroyed minicomputer makers such as DEC, Wang, Apollo and so on. Yet, they do not often disrupt the entire industry. However, in recent years, more industry-wide disruptions have occurred due to emergence of not a single radical innovation but an array of them from within or outside of a particular industry. In this process, it is not just the incumbent market leader or a few incumbent firms but the entire value chain, ecosystem or industry that get displaced. This so-called paradigm shift can be seen in many examples such as GPS device displaced by software companies such as Google and Waze, desktop computing disrupted by mobile devices, and the traditional auto industry centered around the internal combustion engine threatened by peer-to-peer service providers (e.g., Uber), consumer electronics (e.g., Apple), battery-driven vehicle (e.g., Tesla), and software companies (e.g., Google, Amazon). When this happens, incumbents are not fighting against a particular firm or a few firms that have introduced radical innovations based on similar technologies, but an army of very diverse entrants that potentially disrupt entire industries from various directions, some even from remote industries with vastly different organizational capabilities, mind sets and business models. How incumbents of an existing ecosystem should best cope with the massive and dramatic industry-level disruption induced by multiple radical innovations along a number of fronts has largely remained unexamined. 
In the face of paradigm shift, can the strategies or tactics for incumbents to combat single radical innovation or firm be adequate to deal with this new type of multi-faceted existential threat? If not, what should be the appropriate strategies for them to survive or even thrive in the advent of a paradigm shift? In this paper, we attempt to sketch out a research framework to investigate this important issue.

\section{Paradigm Shift and Its Implications}

Paradigm Shift Defined

Paradigm shift has become a popular word and a simple Google search generated close to 7 million entries, much more than that for another popular term "disruptive innovation", (3 million entries). Yet, just like disruptive innovation, paradigm while widely used has never been clearly defined. This term was first coined by Kuhn (1962) in the context of scientific research, meaning a fundamental change in the basic concepts and experimental practices of a scientific discipline. Since the 1960s, it has also been used in numerous non-scientific contexts to describe a profound change in a fundamental model or perception of events. In the late 1990s, "paradigm shift" became a buzzword especially with the rapid growth of high-tech industries and web-based business in the U.S. and work from writers such as Moore (1991).

In the context of technology and innovation, a paradigm is characterized as "pattern of solution of selected technological problems, based on selected principles derived from natural sciences and on selected material technologies "(Dosi, 1982, p. 152), or "a collectively shared logic at the convergence of technological potential, relative costs, market acceptance, functional coherence and other factors" (Perez, 2009, p. 5), and a paradigm shift is "a significant change in the 'problem field' in innovation research, policy making and practice" (Baldwin \& von Hippel, 2011, p. 1400). In other words, a paradigm shift represents a fundamental shift to a different or new technology platform and business practices at the industry level. 


\section{Strategic Implications}

Paradigm shift has very different strategic implications compared to a single radical innovation. First, paradigm shift often encompasses a number of radical innovations occurring in an existing ecosystem or industry. So, it exerts far more disruptive impact on members of the existing industry and can be much more detrimental to their existence. Therefore, incumbent firms cannot often address this existential threat by adopting the appropriate strategies and tactics typically prescribed to deal with a radical individual innovation. Second, it is not just the response of a single incumbent or a group of them that matters, but that of multiple members in the value chain or ecosystem, including the customers. This is because the competition no longer occurs at the firm level but at the ecosystem or industry level. It is battle between ecosystems instead of firms. Thus, the coordination and collaboration among members of existing ecosystem is vital for their collective survival. Third, paradigm shift is not just about technological discontinuity, but radical changes along multiple aspects of value creation, distribution and appropriation. Incumbent firms are under pressure to undergo a dramatic transformation in its technology, business model, organizational form, corporate culture and organizational capabilities or competences in order to survive and then thrive. Such drastic organizational transformation is extremely difficult even for the most competent firms as Nokia, Kodak, Dell, Blockbuster, Blackberry and alike indicated, as such transformation is competence-destroying (Tushman and Anderson, 1986).

\section{Incumbents' Responses and Dilemma}

Surviving radical innovation requires incumbents to radically reconfigure itself along all important organizational dimensions (Ansari \& Krop, 2012), let alone for a paradigm shift. However, incumbents inevitably face a dilemma in moving forward that has at least four aspects. First, the outcome of a paradigm shift can never be clear from outset, just like assessing which innovation would be disruptive (Danneels, 2004; Tellis, 2006). Amid multiple future scenarios, which bandwagon to get on is a very tricky question for incumbents. To hedge future risk, they would need to invest in multiple 
scenarios but committing to more than one path forward is highly resource demanding. So, the first dilemma for them is: should they strategically focus on one scenario or invest in multiple scenarios? Single scenario focus enables them to be fast and efficient in undertaking a radical transformation but also risks them being left out if making the wrong choice. However, investing multiple scenarios will spread their resources too thin to be effective in successfully executing any of the chosen options.

Second, paradigm shift takes time as entrants would need to stitch their own ecosystems often from scratch (Brandenburger \& Nalebuff, 1996; Teece, 1986). In this process, a dominant design often needs to emerge (Utterback, 1994; Suarez, 2004), to enable the efficient establishment of a new ecosystem through standardizations and build-up of the supplier network for complementary products and services. Incumbents would need to act swiftly but moving too fast also carries its own risks. It may be safer to let others to first experiment with radical innovations, as the probability of success increases due to learning effects (Peters and Waterman, 1982). However, acting too slowly, may render the incumbent's business obsolete through the advent of a new paradigm.

Third, paradigm shift requires the coordinated efforts of the entire ecosystem as firms do not operate in isolation but as part of a tightly knitted system (Wareham, Fox \& Giner, 2014). Due to the interdependence among all members of the value network, incumbents would need to mobilize them to collectively migrate into the new paradigm. However, many of the value chain members are also competitors to each other. How to work with one's enemy to achieve a common goal? In other words, where and how much to cooperate and compete with one's rivals? To achieve effective coordination and collaboration, one would need to share more information and resources, yet by doing so, an incumbent firm may make itself more vulnerable. This is a classic dilemma that firms encounter in a coopetitive situation (Brandenburger \& Nalebuff, 1996). Without an efficient and effective coordination mechanism allowing the value chain members to achieve an optimal level of coopetition, existing paradigm will lock itself into the chickenand-egg problem and await total disruption. 
Fourth, disruptors when constructing their own value networks may also include ecosystem incumbents to succeed (Eisenmann, Parker \& Van Alstyne, 2006), as they may need the support of the very incumbents whom they want to disrupt (Ansari, Garud, \& Kumaraswamy, 2015). The key question for incumbent firms is how much to accept or resist and even retaliate these disruptors (Markman and Waldron, 2014). Accepting the invite allows incumbent firms to quickly immerse themselves into the new paradigm and possibly make the transition more naturally, yet it may also help disruptors expedite their disruptive efforts against the entire existing paradigm and ecosystem. It is again a rather delicate situation for incumbents to deal with.

\section{Auto Industry's Paradigm Shift}

Auto industry represents a classic situation for an ongoing paradigm shift. This industry has been characterized by technologies related to internal combustion engines (ICE) for over a century, e.g., ICE paradigm. However, in recent years, major forces have been reshaping this industry profoundly. Industry experts argue that these forces are giving rise to four disruptive technology-driven trends, e.g., connectivity, electrification, autonomous driving and diverse mobility (McKinsey report, 2015, 2016). Customer demand for car connectivity is increasingly at a very high speed, such as driving-related applications and services provided by vehicle-to-infrastructure (V2I), vehicle-to-vehicle (V2V), and communications technologies integrated with the Internet of Things. Electric and fuel-cell powertrains offer higher energy efficiency, lower emissions, greater energy diversity and new vehicle designs. Autonomous drive technology is progressing rapidly led by companies such as Google and Uber. Driverless cars will soon become a commercial reality. Younger generations along with urbanites are gravitating toward a model of personal mobility consumption based on pay-per-use rather than upfront purchase of a capital asset, which fundamentally challenges today's consumption model centered on personal ownership of cars (Deloitte report, 2015).

Behind each of these major disruptive technology trends, there exists a large number of diverse radical innovations in product, technology and business 
models led by firms primarily from different and even remote industries, such as Google, possibly Apple and Amazon as well (autonomous driving), Tesla, and BYD (electrification), Uber, Lyft, Didi Kuaidi, Zipcar and alike (individual or shared mobility). These entrants and their radical innovations are attacking the auto industry from multiple fronts and very likely to uproot the entire industry as they are turning a car into more of consumer electronics, or more precisely a mobile computer on the road, e.g., the merger of autobahn and infobahn (Seidel, Loch, \& Chahil, 2005), which has the potential to be a hub for human being's intelligent life or a platform consolidating all essential services in modern life. Besides radically redefining the car categories, these disruptors are also redefining the very meaning of transportation and moving the entire human society towards a personalized mobility service era. In many ways, the auto industry's paradigm shift is not just the shift from ICE one into an electric one or autonomous one, but multiple paradigm shifts occurring at different levels with varying magnitude within the auto industry. Moreover, these forces will reinforce and accelerate one another, and the convergence of disruptive technology-driven trends will likely transform the auto industry (McKinsey report, 2016), and induce a massive paradigm shift at a rapid pace. In the new paradigm, new ecosystems can emerge. OEMs and other players could cooperate using the same (software) platform to aggregate driver data and provide application programming interfaces to third-party developers to offer additional services, very similar to the PC industry (McKinsey report, 2015).

\section{Auto Makers' Strategic Considerations}

The auto industry will inevitably be transformed into a PC industry-like one and all auto makers will have to pursue the "autobahn merges with infobahn" path by bringing connectivity into their cars just to be able to stay in the core business (Seidel, Loch, \& Chahil, 2005). Moreover, they need to transform themselves into personal mobility service providers or at least making the service a key component of their business models and operations. Not only because it future consumer needs may evolve in this direction, but also because once a car becomes a PC-like device, massive influx of firms from emerging economies (lowered barrier to entry) will drastically bring down profitability in the hardware manufacturing part of the value chain. Existing 
players will have to move into high- or ultra-high end segments of the market or the mobility service, in particular, the seamless multimodal transportation service (Deloitte, 2015).

For a high-end car maker such as Jaguar Land Rover, the first and foremost task is to pursue the enhancement and development of capabilities needed for a vastly different future. In other words, what core competence JLR would need to obtain? How should JLR develop software capabilities? How to develop a service capability if entering mobility service is inevitable? In a more turbulent future, rapid responsiveness is a critical organizational competence to have, but how should JLR develop it? Organizational competence is largely shaped by the need to provide desired value propositions for the target customers, but what would be the future value propositions for JLR's customers? What can be a meaningful differentiation for JLR brand?

Moreover, what business model should be designed to give JLR the flexibility to work with alternative future scenarios? What kind of organizational profile should JLR have in better preparing for the radical paradigm shift? Research indicates that OEMs will likely need to push an end-to-end digitalization of their organizations and build up skills for software development to fulfil new requirements. (McKinsey \& Company, 2015). How should JLR digitalize itself and then provides customers with a digitalized total brand experience? As JLR is much smaller than its key competitors, such as Audi, pursuing all innovation in house appears to be infeasible. So, how should JLR work with external technology companies, especially small firms and start-ups in emerging technology areas and software development? Most importantly, existing ecosystems within the auto industry may dissolve and new ones gradually take shape. How should JLR develop a vibrant ecosystem such as by owning its own platform or by become a key member of it?

\section{Research Questions on Incumbent's Response to Paradigm Shift}

Paradigm shift and incumbent's response, despite of its importance in both theoretical and managerial fronts, have only been examined very sparsely. Many questions warrant further investigation. First, how should incumbents address the four "incumbent's dilemma" in dealing with paradigm shifts? 
Second, within a more complex and diversified mobility industry landscape, incumbent players will be forced to simultaneously compete on multiple fronts and cooperate with competitors (McKinsey report, 2016). So, how should incumbents cope with multiple radical innovations and challengers? Third, how should incumbents cooperate with competitors from both new and existing ecosystems? Fourth, what are the key drivers for incumbent's successful migration into a new paradigm? Fifth, how should incumbents better predict the most likely future scenario of a paradigm shift? Sixth, what are the organisational capabilities required for such a successful migration? Seventh, how should incumbents develop a platform strategy in the face of a paradigm shift? Eighth, how can incumbents effectively obtain a different set of organizational competences or dramatically transform its existing ones?

Furthermore, there always exists inherent uncertainty regarding the outcome of a paradigm shift. It is thus vital for incumbents to be flexible. It is important to investigate how should incumbents pursue strategies that address the converging forces incrementally, creating future option value while preserving flexibility? To be better prepared for this incoming paradigm shift, most major auto makers have set up offices in Silicon Valley to gain greater proximity to technology development and early-stage funding, e.g., Ford's 25 mobility projects, BMW's iVentures, and so on (Deloitte, 2015). It is thus interesting to examine whether such efforts would prove to be effective in achieving their goals or how to make them more effective.

\section{References}

Ansari, S., Garud, R., \& Kumaraswamy, A. (2015). The disruptor's dilemma: TiVo and the U.S. television ecosystem. Strategic Management Journal, $37(9), 1829-1853$.

Ansari, S., \& Krop, P. (2012). Incumbent performance in the face of a radical innovation: towards a framework for incumbent challenger dynamics. Research Policy, 41, 1357-1374.

Baldwin, C., \& von Hippel, E. (2011). Modeling a paradigm shift: from producer innovation to user and open collaborative innovation. Organization Science, 22(6), 1399-1417. 
Brandenburger, A., \& Nalebuff, B. (1996). Coopetition: a revolution mindset that combines competition and cooperation, the game theory strategy that's changing the game of business. New York: Currency Doubleday.

Christensen, C. M. (1997). The innovator's dilemma: when new technologies cause great firms to fail. Boston: Harvard Business School Press.

Danneels, E. (2004). Disruptive technology reconsidered: a critique and research agenda. Journal of Product Innovation Management, 21(4), 246258.

Deloitte Consulting LLP. (2016). The future of mobility. White Paper, Deloitte University Press.

Dosi, G. (1982). Technological paradigms and technological trajectories. Research Policy, 11, 147-162.

Eisenmann, T., Parker, G., \& Van Alstyne, M. (2006). Strategies for two-sided markets. Harvard Business Review, 84(10), 92-101.

Hill, C. W. L., \& Rothaermel, F. T. (2003). The performance of incumbent firms in the face of radical technological innovation. Academy of Management Review, 28(2), 257-274.

Ghemawat, P. (1991). Market incumbency and technological inertia, Marketing Science, 10(spring), 161-171.

Kuhn, T.S. (1962). The structure of scientific revolutions: Chicago: University of Chicago Press.

Markman, G.D., \& Waldron, T.L. (2014). Small entrants and large incumbents: a framework of micro entry. Academy of Management Perspectives, 28(2), 179-197.

McKinsey \& Company. (2015). Competing for the connected customer: perspectives on the opportunities created by car connectivity and automation. September, White Paper.

McKinney \& Company. (2016). Automotive revolution - perspective towards 2030. January, White Paper. 
Moore, G. A. (1991). Crossing the chasm: marketing and selling high-tech products to mainstream customers: New York, Harper Business Essentials.

Perez, C. (2009). Technological revolutions and techno-economic paradigms. Cambridge Journal of Economics, 34(1), 185-202.

Peters, T.J., \& Waterman, R.H. (1982). In search of excellence, New York: Harper \& Row.

Seidel, M., Loch, C. H., \& Chahil, S. (2005). Quo Vadis, automotive industry? A vision of possible industry transformations. European Management Journal, 23(4), 439-449.

Suarez, F. F. (2004). Battles for technological dominance: an integrated framework. Research Policy, 33(2), 271-286.

Teece, D. (1986). Profiting from technological innovation: implications for integration, collaboration, licensing and public policy. Research Policy, 15, 285-305.

Tellis, G. J. (2006). Disruptive technology or visionary leadership? Journal of Product Innovation Management, 23(1), 34-38.

Tushman, M.L., \& Anderson, P. (1986). Technological discontinuities and organizational environments. Administrate Science Quarterly, 31, 439-465.

Utterback, J. M. (1994). Mastering the dynamics of innovation. Boston: Harvard Business School Press.

Wareham, J., Fox, P., \& Giner, J. (2014). Technology ecosystem governance. Organization Science, 25(4), 1195-1215. 